\section{Final diagnosis}

Peripheral neuropathy secondary to pyogenic liver abscess.

1 Bolton CF. Sepsis and the systemic inflammatory response syndrome: neuromuscular manifestations. Crit Care Med 1996;24:1408-16.

2 Vukmir RB. Pyogenic hepatic abscess. Ann Emerg Med 1991;20:421-3.

3 Sridharan GV, Wilkinson SP, Primrose WR. Pyogenic liver abscess in the elderly. Age Ageing 1990;19:199-203.
Keywords: peripheral neuropathy; hepatic abscess

4 Young AE. The clinical presentation of pyogenic liver abscess. Br F Surg 1976;63:216-9.

5 Teitz S, Guidetti-Sharon A, Manor H, Halevy A. Pyogenic liver abscess: warning indicator of silent colonic cancer. Dis Colon Rectum 1995;38:1220-3.

\title{
Hypercalcaemia with radiographic abnormalities in chronic myeloid leukaemia
}

\author{
N Sharma, S Jain, S Kumari, S Varma
}

A 56-year-old woman with untreated chronic myeloid leukaemia presented with a history of weakness, easy fatigability and fever of 6 weeks duration. She was emaciated, pale, had sternal tenderness and a few palpable lymph nodes in the cervical, axillary and the inguinal areas. General physical examination showed splenomegaly $(2 \mathrm{~cm}$ below the left costal margin). Laboratory investigations revealed a haemoglobin level of $8.5 \mathrm{~g} / \mathrm{dl}$; a total leucocyte count of $125 \times 10^{9} / 1$ with $35 \%$ neutrophils, $4 \%$ lymphocytes, $1 \%$ monocytes, $37 \%$ eosinophils, $2 \%$ basophils, $1 \%$ promyelocytes, $10 \%$ myelocytes, $6 \%$ metamyelocytes, and $4 \%$ blasts, and there were $3-4$ nucleated red blood cells per 100 white blood cells. The peripheral blood smear showed microcytic and elliptocytic red blood cells. The platelet count was $200 \times 10^{9} / 1$. The serum biochemistry showed a serum calcium of $3.6 \mathrm{mmol} / \mathrm{l}$, serum albumin $26 \mathrm{~g} / \mathrm{l}$, serum phosphorous $1.3 \mathrm{mmol} / \mathrm{l}$ and serum alkaline phosphatase 241.4 IU/1 (normal 21.3-92.3 IU/1). Estimation of the 24-hour urine sample showed a calcium excretion of $660 \mathrm{mg}$ (normal $100-300 \mathrm{mg}$ ) and a phosphorous excretion of $1580 \mathrm{mg}$ (normal 600-1200 mg). The bone marrow of this patient was hypercellular with depressed erythropoiesis and a differential count of $12 \%$ blasts, $2 \%$ promyelocytes, $2 \%$ myelocytes, $3 \%$ metamyelocytes, $44 \%$ neutrophils, $3 \%$ lymphocytes, $2 \%$ monocytes and $32 \%$ eosinophils. The leucocyte alkaline phosphatase score was 42 (normal 35-140) and the trephine biopsy disclosed coarse deposition of reticulin. Photographs of the X-rays and a Technetium ${ }^{99 m}$ bone scan images are displayed in figures 1 and 2, respectively.

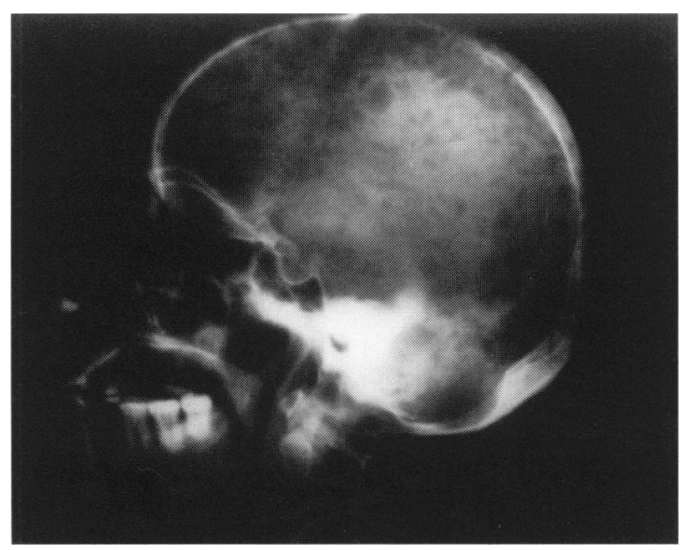

Figure 1 X-ray of the skull, lateral view

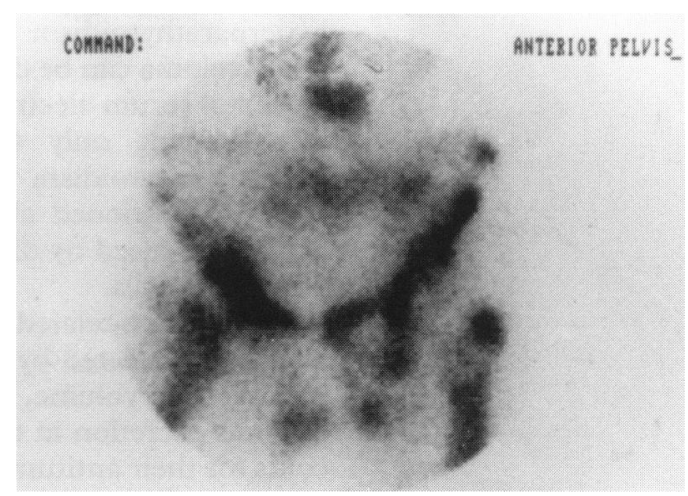

Figure 2 Technetium ${ }^{99 m}$ bone scan of the pelvis
Institute of Medical

Education and

Research, Chandigarh, India 160012

N Sharma

S Jain

S Kumari

$S$ Varma

Correspondence to $\mathrm{Dr}$ Sanjay Jain

Accepted 25 November 1997

\section{Questions}

1 What do the haematological parameters and the bone marrow findings of this patient indicate?

2 What does the serum biochemistry and analysis of the 24-hour urinary sample disclose? List the different conditions that can cause this state.

3 What do the $\mathrm{X}$-ray and the radionuclide scan depict? List the conditions that can manifest with such a picture and give their appropriate treatments. 


\section{Answers}

QUESTION 1

The haematological profile of this patient with chronic myeloid leukaemia (CML) shows anaemia, leucocytosis and a differential leucocytic count compatible with the basic diagnosis. In addition, eosinophilia and the presence of some immature red cells in the peripheral blood smear may indicate either conversion to the accelerated phase, blast crisis or the presence of myelofibrosis. The diagnosis of CML in the accelerated phase with myelofibrosis is confirmed by the presence of a normal leucocytic alkaline phosphatase score, eosinophilia, anaemia, myelofibrosis and an increased number of blast cells in the marrow (not a blast crisis, in which the blast plus promyelocyte cell count should be more than $30 \%)^{1{ }^{2}}$

\section{QUESTION 2}

The serum biochemistry shows hypercalcaemia with a normal serum phosphorous and raised serum alkaline phosphatase. This profile can occur only in three states:

- excessive parathyroid activity (primary or due to ectopic production)

- humoral hypercalcaemia of malignancy due to the production of a parathyroid hormone related peptide

- direct osteolytic activity by malignant cells. The state of excessive parathyroid activity and that of its related peptide are accompanied by a low urinary excretion of calcium and hyperphosphaturia. Thus, the high serum calcium in this patient is attributed to direct osteolytic tumour invasion by leukaemia cells.

\section{QUESTION 3}

The X-ray of this patient shows generalised osteopenia and numerous lytic lesions in the skull while the radionuclide scan shows many spots of increased radiotracer uptake in the pelvis (multiple foci) indicating the existence of generalised osteoclastic bone resorption. Such a picture can occur with multiple myeloma, hyperparathyroidism and osteolytic secondaries. Myeloma can be discounted on the basis of a normal serum electrophoresis and bone marrow showing only $4 \%$ plasma cells, while hyperparathyroidism is ruled out for the reasons mentioned above. Thus, this picture has been caused by direct osteolytic activity of leukaemia cells.

Malignancy-related hypercalcaemia can be adequately treated by hydration to restore the intravascular volume, loop diuretics to enhance calcium excretion in the urine and glucocorticoids for their antitumour effects, until specific treatment for the underlying tumour can be administered. In this case the ideal treatment would be a bone marrow transplantation, pro-

1 Kantarjain HM, Dixon D, Keating MJ. Characteristics of the accelerated disease in chronic myeloid leukaemia. Cancer 1988;61:1441-6.

2 Neuhelk SD, McKenna RW, Arthur DC, et al. Transformation of chronic granulocytic leukaemia: clinical, morphologi$\mathrm{cal}$ and cytogenetic features. Am f Clin Pathol 1984;8:1-4.

3 Fisken RA, Health A, Bold AM. Hypercalcaemia: a hospital survey. $Q \mathcal{F}$ Med 1984;196:405-18.

\section{Summary points}

- hypercalcaemia as a metabolic emergency occurs in $0.5 \%$ of hospitalised patients

- malignancy-related hypercalcaemia usually occurs as a complication of specific tumours (lung, head, neck, breast and oesophagus)

- haematological malignancies account for $10 \%$ of all tumour-associated hypercalcaemia

- hypercalcaemia can occur in the accelerated or the blastic phase of chronic myeloid leukaemia and can be adequately treated by hydration, loop diuretics and glucocorticoids

vided that an HLA-matched donor is available. Anticancer drugs like hydroxyurea or cytarabine can be used to control the raised cell count and interferon-alpha in high doses for its antiproliferative effects.

\section{Discussion}

Hypercalcaemia is one of the common metabolic emergencies occurring in $0.5 \%$ of hospitalised patients. ${ }^{3}$ Malignancy-related hypercalcaemia is usually seen complicating specific types of tumours, ie, carcinomas of lung, head, neck, breast and oesophagus. ${ }^{3}$ Carcinoma of the breast accounts for nearly $20-25 \%$ of cases, and together with lung carcinoma, the figure approaches $60 \% .^{34}$

Haematological malignancies account for $10 \%$ of cases of tumour-associated hypercalcaemia, the majority of which are leukaemias, myelomas, lymphomas and HTLV-I associated leukaemias/lymphomas. ${ }^{3}$

Hypercalcaemia associated with CML, with or without destructive bone lesions, is uncommon. ${ }^{35}$ This hypercalcaemia is usually attributed to bone destruction by the leukaemic cells ${ }^{6}$ but ectopic production of parathyroid hormone has been seen in one case, while another case report has documented increased levels of urinary cyclic adenosine monophosphate. ${ }^{7}$ In contrast, most of the other reported cases of CML presenting with hypercalcaemia were conspicuous by normal levels of parathyroid hormone and cyclic AMP.5689 The survival time of CML patients after the recognition of hypercalcaemia is reported to be from a few days to 7 months..$^{5-10}$

\section{Final diagnosis}

Malignancy-related hypercalcaemia in a patient with chronic myeloid leukaemia.

Keywords: malignancy-related hypercalcaemia; chronic myeloid leukaemia

4 Nussbaum SR. Pathophysiology and management of severe hypercalcaemia. Endocrin Metabol Clin North Am 1993;22. 343-62.

5 Ballard HS, Marcus AJ. Hypercalcaemia in chronic myelogenous leukemia. $N$ Engl 7 Med 1970;282:663-5.

6 Kubota K, Yanagisawa T, Kurabayashi H, et al. Hypercalcaemia associated with osteolytic lesions in the extramedul- 
lary blastic crisis of chronic myelogenous leukemia: report of a case. Blut 1989;59:458-9.

7 Molho P, Grange MJ, Gueris J. Hypercalcaemia in chronic myeloid leukemia: evidence for excessive parathyroid hormone secretion. Nouv Rev Fr Haematol 1985;27:189-92. 8 Attar E, Prokocimer M, Januszewicz E, Theodor E. Hyper8 Attar E, Prokocimer M, Januszewicz E, Theodor E. Hyperof chronic myeloid leukemia. Acta Haematol 1988;79:211-2.
9 Walter M, Greenberg BR. Hypercalcaemia in the accelerated phase of chronic myeloid leukemia. Cancer 1980;46: 1174-8.

10 Hasselbalch H, Birgens HS, Geisler C, Hansen NE. Hypercalcaemia in the accelerated phase of chronic myeloid leukemia. No relationship to the phenotype of the blast cells. Scand $\mathcal{F}$ Haematol 1985;35:333-8.

\title{
Renal calculi following superior mesenteric artery occlusion
}

\author{
L Ranganath, S R Gould, P F Goddard
}

A 48-year-old woman developed an occlusion of the superior mesenteric artery resulting in infarction of the jejunum, ileum and proximal colon up to the splenic flexure. She underwent extensive small intestinal resection followed by a jejunocolic anastomosis; the residual jejunal length was $35 \mathrm{~cm}$. She was morbidly obese prior to intestinal resection (weight $102 \mathrm{~kg}$; BMI 45.7) and steadily lost weight following the surgery. Initially, she experienced marked diarrhoea post-resection; this improved until she was experiencing four to eight bowel movements daily.

She re-presented two years later with painless haematuria when she was found to have multiple calculi in the left kidney. She underwent lithotripsy following which a temporary renal stent was inserted for six months. Baseline serum electrolytes, calcium and liver profiles as well as 24-hour urine calcium and urate excretion at this time were normal. She had significant renal impairment with subnormal creatinine clearance as well as raised serum creatinine and urea following this episode, which resolved partially. She was advised to go on a low-calcium diet.

She was re-evaluated three years following intestinal resection when her body weight was 53.5 $\mathrm{kg}$ (BMI 23.6). She continued to have frequent bowel movements and was almost certainly mal-

Epsom General Hospital, Epsom, KT18 7EG, UK Department of Chemical Pathology

L Ranganath

P F Goddard

Department of

Medicine

S R Gould

Accepted 19 November 1997 absorbing. She had noticed foul smelling and pale faeces which were difficult to flush. Cholestyramine therapy had no effect on the diarrhoea although some relief was obtained with codeine phosphate.

\section{Questions}

1 What is the cause of the renal calculi in this woman?

2 Comment on the dietary advice she was following at the time of presentation.

3 What further investigations would you perform?

4 What further therapy would you consider? 